\section{La protección de datos personales en Colombia.}

Desde un análisis socio-jurídico del derecho a olvido en la era digital

The protection of personal data in Colombia. A socio-legal analysis of the right to be forgotten in the digital age.

Liz Colombia De la Vega Avendaño' - Keyla Julieth Novoa Arzuaga ${ }^{2}$

RECIBIDO: 12-09-16 ACEPTAD: 24-04-16 PUBLICADO: 09-01-17

\section{RESUMEN}

Se dará a conocer en esta ponencia el sistema de la protección de datos en Colombia y el derecho que existencia buscando los fundamentos para que ponga límites a la perennidad de la información en linea. A partir del derecho a la protección de datos y del derecho a la intimidad o a la vida privada es posible articular la Palabras clave: Derecho Al Olvido, Habeas Data, Libertad De Expresión En Internet, Derecho A La Intimidad
Y A Debido Proceso Derechos ARCO

\section{ABSTRACT}

this research will be released the data protection system in Colombia And the right to be forgotten in the network, starting from its concept and its historical evolution, and conflict over the existence, extent and
limits of the denominated The Right To Be Forgotten based on iurisprudential study, searching the fundamentals to put limits on the permanence of online information.

From the right to data protection and of the right to privacy or the private life is possible to articulate the

Keyword: the right to be forgotten, Habeas Data, Freedom of Expression On The Internet, Right To Privacy
And Due process, ARCO Right

\section{INTRODUCCIÓn}

El término "derecho al olvido" a simple vista denota que se trata de que se olviden, pero va más allá de ese suceso; Este término lleva a la protección de nuestros derechos a la intimidad, a nuestro honor 0 a nuestra imagen que en muchos casos se ve expuesta; $A$ veces por ignorar, por no instruirse, los seres humanos cometemos errores a mostrar nuestra intimidad al público, en las herramientas más utilizadas por los jóvenes, hoy en día son las plataformas virtuales o redes sociales, entre ellas el Facebook en el cual un sin números de adolescentes lo utilizan de forma errónea realizando publicaciones acerca de su vida personal, sin saber diferenciar el espacio físico y el espacio digital.

Los grandes avances de la tecnología han traído consigo grandes ventajas y desventajas, pues estas herramientas las cuales cada día van aumentando dependiendo las necesidades de un mundo globalizado, exponiendo la vida asi la privada de personas sin pensar en cómo llegaría afectar su familia, su profesión; en caso muchos no entienden lo delicado que es estar expuesto ante la luz pública. su vida se podría afectar en diferentes aspectos como perder su empleo, dañar su hoja de vida, podría hasta ocurrir que perdiera sus amigos o familia y todo lo que ha construido se le desvanezca en menos de un segundo, solo por el hecho de no tener el cuidado con las plataformas o la información que está suministrando.

Sin ir tan lejos para saber información sobre una persona podemos utilizamos uno de los buscadores más conocidos google al teclear un nombre este nos arroja toda la información posible que pueda aparecer de esa persona, hemos visto casos de personas que utilizan el buen nombre de otras y se hacen pasar por ellas, sus fotos, su información personal, número de celular o simplemente para no mostrarse tal cual se inventan una doble identidad y la verdad no es necesario conocer a la persona, solo basta colocar un nombre en el buscador cualquiera persona puede crear un perfil falso, tomar su vida y hacerse pasar por esa persona sin saber que eso adhiere a un delito y son casos que pasan diariamente y ningún está absuelto de que algún día podría ser víctima de esto.

Lo más alarmante es la inmediatez con la que uno puede obtener esos datos y hacer uso de ellos, sin medir las consecuencias y lo peor de todo que no hay nada que impida que eso siga ocurriendo, no existe manera de prohibir o por lo menos privatizar nuestra información personal en esta era digital. 
Al principio todos veíamos que si nuestro nombre aparecía en el buscador éramos famosos, pues asi pensaba uno más joven, pues al ver noticias, los casos de violación a la identidad privada, pues uno se cuestiona si eso es factible si es normal que nuestros datos personales aparezcan asi de la nada con solo teclear un dato nuestro o un nombre. Es hora de cuestionarnos y preguntarnos qué debemos hacer para parar esto y que las autoridades competentes se enfoquen en este caso que es primordial para muchos y se nos respeten nuestro derecho a la intimidad y la cual no sea exhibida de esa forma.

Seguidamente, se presenta el derecho al olvido en la Sentencia T-277/15 de la corte constitucional de Colombia instaurada por Gloria contra la Casa Editorial Tiempo por considerar violados sus derechos fundamentales al buen nombre, la intimidad, el debido proceso, de petición y al trabajo. La alegada vulneración se habría derivado de la publicación de una nota periodística en la que se informaba sobre la supuesta participación de la accionante en hechos constitutivos de delito, en relación con los cuales nunca fue declarada culpable, asi como la posterior indexación de dicho contenido por el motor de búsqueda Google.com. (Corte Constitucional, 2015)

La sentencia T-020/14 instaurada por la señora xx contra la sala plena de la corte suprema de justicia al considerar que se le estaba violando su derecho fundamental a la dignidad humana, a la igualdad, al buen nombre y a la honra. La alegada vulneración se habría derivado de la aparición de su nombre en la que sus antecedentes penales por los delitos de concusión, falsedad material de particular en documento público y fraude procesal del cual el afectado había cumplido la pena y había hecho su proceso de rehabilitación. Tras indagar por su nombre en el buscador Google, encontró que, en la página web de la Corte Suprema de Justicia, figuran anotaciones alusivas al proceso penal, incluidas ambas instancias. (Corte constitucional, 2014)

\section{METODOLOGIA}

Esta ponencia es cualitativa de carácter Documental, en la que se traza como objetivo analizar una visión global del mundo jurídico en la protección de datos personales, con una interpretación de la realidad social en su forma empírica, con el propósito de establecer relaciones, diferencias, etapas, posturas o estado actual del conocimiento respecto del tema objeto de estudio y demás paradigmas jurídicos.
El método utilizado comportará un enfoque cualitativo que permitirá describir detalladamente y dar a conocer todas las aristas del derecho al olvido en Colombia en la era digital entendido como un derecho innominado, que tiene correlación con el Habeas Data y la protección de datos personales.

\section{EL DERECHO AL OLVIDO COMO PROYECCIÓN DEL DERECHO A LA}

\section{PROTECCIÓN DE DATOS}

El derecho a la protección de datos es un derecho esencial, el cual esta establecido en la constitución y consiste en otorgarle un poder o un control sobre los datos personales de un individuo y que este decida cuales de esos datos podría suministrar a un tercero para que haga uso de ellos, pero teniendo en cuenta siempre que es bajo la aprobación de la persona que otorga el poder

La persona que proporciona la información debe tener pleno conocimiento de saber quién es el tercero que va hacer uso de sus datos y para qué los utilizará, solo así esa persona quedará totalmente tranquila de que el tercero no hará uso indebido de sus datos, así de esta manera evitará problemas o malos entendidos más adelante pero siempre teniendo la completa certeza de eso del uso que se le dé.

La mayor problemática hoy por hoy es el uso inadecuado que le dan al internet y es a partir de este punto que se debe manejar la parte de la protección de datos, que dichos datos se cobijen a una normativa específica y puedan ser tratados a partir de ahí, estableciendo parámetros y haciéndolos cumplir a medida como avancen.

Si se mira esto desde un punto de vista más ambiguo, desde el nacimiento del internet, buscar cualquier cosa es más fácil de lo que uno cree, un nombre una dirección, un teléfono, entre otras muchas cosas que son parte de la vida privada de cada persona, antes no se presentaba dicho problema pero el internet cada vez se ha vuelto el centro de todo, cualquier dato que necesites, la internet te lo manifiesta y va arrojando consigo un sin números de información para que este alcance de la persona que lo solicita. Pero eso ahora se ha vuelto un peligro para la sociedad como tal, ya nadie está absuelto de que utilicen su información personal para beneficio de otras personas y asi acarrearle un problema de suma importancia a la victima de este hecho. 
Por eso inquirir a un mecanismo para que suprima y se oponga a que la internet suministre la información de cada persona sería lo más justo y beneficioso este momento ya que permitirían la protección en el interés de las personas ante el derecho del olvido digital.

En muchos otros países ya este derecho se ha hecho sentir como otros que también andan pidiendo camino para poder salir y han optado porque este derecho se note cada vez más, manteniendo seguros sus datos y garantizándoles un cambio de opinión acerca de esto. En Italia la Autoridad Nacional correspondiente ha venido acogiendo de forma favorable las peticiones de personas que han sido afectadas con esta problemática, de las cuales su información personal se ha divulgado de una u otra forma y les ha ocasionado un sin múltiplo de dificultades en cada área de su vida personal y profesional.

En ciertos países además se le otorga a la persona un derecho que equivale a la cancelación de los datos personales cuando estos han sido publicados sin el consentimiento de la persona. Es bueno tener conocimiento que esto acarree un problema ante la ley puesto que esa información suministrada no es aprobada por la persona pertinente. Pues una vez bloqueados los datos los terceros no tendrían acceso a esa información y de esta manera poco a poco se va protegiendo la información suministrada.

\section{FUNDAMENTOS JURIDICOS DEL DERECHO AL OLVIDO COMO PROYECCIÓN A}

\section{LA PROTECCIÓN DE DATOS}

Muchas son las preguntas que se hacen diariamente los habitantes, y pocas son las respuestas que obtienen por parte y parte, si hay algo que no está claro es el concepto del término derecho al olvido y su función en sí. Jurídicamente se puede definir como aquel fundamento jurídico que permite que ciertas informaciones pasadas no sean difundidas actualmente y/o en un futuro remoto las cuales son capaces de causar más daño que un beneficio a la persona.

s por esto que se provee el ejercicio del beneficio a la libertad de expresión un derecho fundamental para la persona, el cual pueda hablar sin importar las circunstancias infiriendo así los daños provocados por los bienes jurídicos. s por esto se busca la retirada de cuyos elementos afectan y cuestionan la reputación de la persona víctima de este mal hablado sistema que expone de manera publica su información la cual debería ser netamente privada.
De un tiempo para acá se ha visto la relevancia que ha tenido por los asuntos que están vinculados a la protección de datos personales y una de ellas es el poder identificar el derecho al olvido admitiendo asi una solución similar, como la de solicitar la eliminación de sus datos los cuales son de carácter confidencial e intimas. Una vez las normativas que están asociadas a la necesidad de regular el uso de ciertos datos personales, este debería y podría ser analizado bajo la lógica de los derechos fundamentales y más desde el punto de vista de los conflictos de derechos, ya que este está estrechamente ligado y/o relacionado a la vida privada y familiar.

Este proyecto de la protección de datos podría alcanzar un reconocimiento normativo basado en aumentar la certeza jurídica y facilitar su trabajo judicial. La cual traerá consigo una serie de ventajas y beneficios en su desarrollo que a nivel mundial seria reconocida es lo que aplica este derecho a realizar.

\section{PROTECCIÓN DE DATOS- PRIVACIDAD- IDENTIDAD}

Es importante tener claro los conceptos de estos tres derechos, protección de datos, derecho a la privacidad y derecho a la identidad que de una u otra forma están relacionados pues los tres al final tienen un mismo objetivo que es proteger la información personal de cada persona o usuario del cua internet muestra públicamente exponiendo la identidad de los mismos.

A pesar de que el derecho a la protección de datos se califica como un derecho procesal es decir que su punto es supervisar a los individuos que se encuentran involucrados en dicho proceso y el derecho a la privacidad y el derecho a la identidad son de derechos sustantivos el cual equivale a la implantación de las conductas que deben seguir cada individuo o persona los tres tienden a tener el mismo interés.

Cada uno de esas reglas, métodos y condiciones con el que funciona el derecho procesal busca que se establezcan, apliquen y protejan en el derecho sustantivo. Es importante tener el conocimiento que la libertad de información, a la seguridad o a la libertad de elegir religión hacen parte del derecho de la privacidad del individuo, es algo propio de la persona y que deben ser respetados y no vulnerados como se ha hecho durante todo este tiempo. El derecho a ser olvidado hace referencia a la protección de datos el cual es otro de los más fundamentales pues es este que solicita eliminar la información privada de las plataformas con el fin de evitar más riesgos y mayores peligros. 
Partiendo de que el derecho a la privacidad y el derecho a la identidad comparten el mismo ADN pues estos dos derechos son determinantes, pues ambos buscan proteger aquellos derechos basados en la personalidad del individuo. El opinar diferente a los demás no hace que la persona sea menos que el resto, solo es cuestión de prioridades y cuestión de valerse por sí mismos, a ser únicos lo cual pocas personas pueden entender y comprender.

Se dice que lo que la persona proyecta eso es, "afirmación "que no es del todo cierta, pues a veces por no querer mostrar lo que en realidad es la persona este opta por mostrar una faceta distinta lo conocido por una fachada. Su objetivo: evitar ser conocida como tal. Hoy por hoy el derecho a la identidad personal suele ser el factor más importante pues de eso parte la imagen de la persona la cual se somete a ser juzgada, criticada por terceros, un diario vivir de todos los famosos, entre esos artistas, actores, actrices, cantantes, presentadores entre otros.

Ese grupo de personas día a día se someten a duros comentarios de los usuarios, a una mujer la tildan que está muy gorda, muy flaca, le juzgan su forma de vestir, los insultan por las redes y muchas otras cosas más. Ellos por el solo hecho de dar un punto de vista, montar una foto se objetó ocular de los usuarios y sus comentarios ofensivos, muchos de esos comentarios buenos otros bastantes hirientes, el punto que cada persona es libre de opinar de lo que mejor le parezca, pero evitando comentarios fuera de base. De aquí parte el querer proteger la vida privada de cada quién, para hacer mal uso de esa información.

Al conseguir la eliminación de los datos de los usuarios que han sido expuestos públicamente asi sea por un periodo de tiempo, sería la apertura de un nuevo comienzo en ese camino que se quiere y asi poco a poco cada dato personal que maneja el internet a su antojo se estaría protegiendo.

Hay que tener en cuenta que internet es un plataforma virtual que maneja millones de informaciones de todos los usuarios del mundo entero y que buscar la protección de datos es tema de dedicación y paciencia, pues cada red social infiere en esta parte ya que debe actualizar sus plataformas u herramientas para la protección de cada dato, negocio que solo si se da manejando un fallo ante la justicia solicitando de parte de los usuarios afectados la eliminación temporal o permanente de su información básica personal.
LA IDENTIDAD COMO RAIZ NORMATIVA DEL DERECHO AL OLVIDO COMO

\section{PROYECCIÓN A LA PROTECCIÓN DE DATOS}

La identidad no es más que una construcción cultural y social sobre algo que favorablemente se va construyendo o que se elige basado en el respeto. La identidad personal se puede llegar a tomar como un proceso de negociación continua ya sea entre uno mismo o con los demás. El derecho al olvido es un instrumento que puede ser usado permitiendo así futuras eliminaciones de identidades anteriores.

Cabe resaltar que el derecho a ser olvidado, juega un papel fundamental en el proceso de construcción de la identidad pues permite construir nuevas y diferentes identidades a lo largo de la vida. Pues esto se debe mirar bajo distintas perspectivas. La ley en este caso ha estado reglamentando identidad personal. En esto infiere que el estado ha estado concediendo a la población diferentes instrumentos legales para cambiar aspectos de su identidad. Uno de esos tales instrumentos o permisos por así llamarlos de algún modo es que las poblaciones tienen derechos a cambiarse el nombre, cambiar su sexo, de nacionalidades también con el fin de que la persona se encuentre segura y protegido bajo esta ley reglamentaria. El derecho a eliminar parte de la identidad de una persona suele ser un plus para encajar y tratar de entender lo que busca la ley apoyando esto desde hace mucho tiempo.

Dicha propuesta debe conocer que los derechos de la identidad personal cambian con la evolución y envejecimiento de a la persona. Agregando una pequeña particularidad el derecho a que no se malinterprete ni se calumnie la identidad de la persona. El derecho al olvido en este caso parece encontra una raíz en normatividad siendo este el núcleo del interés y valor siendo este una de las piezas primordiales para lograr el derecho a la identidad personal.

\section{CONFLICTOS Y EQUILIBRIOS}

Uno de los equilibrios esenciales de este derecho es el reconocer que es uno de los pocos derechos ene l que se le efectúa la parte de que está bien constituida su identidad personal ya sea basada por terceros por las percepciones que ellos tienen de los demás. La idea de ser diferentes, de no ser los mismos, de aprovechar oportunidades que brinda la naturaleza y el resto de los recursos no le hace menso que nadie. Las diferencias de opiniones abundan 
y solo hay que saber manejar cada opinión. El derecho a ser olvidado vive en constante presión y conflicto con el resto de los derechos pues cada uno maneja diferentes valores, objetivos e intereses.

Los intereses privados y el derecho a ser olvidado más que efectuar un conflicto deben trabajar en construir un equilibrio frente a los demás derechos, como es el caso de los intereses públicos y sociales los cuales buscan acceder a la información sobre la libertad de expresión. Este derecho abarca muchos items, tales como el de otorgarle al individuo un poder para controlar 0 corregir aquellas imágenes que proyectan de forma pública y de la cuales da oportunidad a terceros de influir o acceder a dichas informaciones o post.

\section{EL DERECHO A SER OLVIDADO FRENTE AL DERECHO A LA MEMORIA Y LA} OBJETIVIDAD

Uno de los mayores conflictos desde la década de los 90, época en el que internet empezó a surgir y ene l que muchas historias pasadas comenzaron a rchivarse de manera digital en una de las tantas plataformas que se había creado. Pero siempre ha sido un motivo de conflicto el de poder conservar y preservar aquella memoria colectiva e histórica frente a tanta burla que ha cuestionado su acción. Pues dichas historias pasadas han sido manipuladas por terceros con fines no muy gratos para los usuarios, mucho de ellos se ha visto afectados y ante tanta manipulación de información a las personas encargadas esta situación se le ha salido de las manos.

Un famoso escritor llamado Paul Choudhury señala lo siguiente: «todos estos datos resultarán fascinantes para los sociólogos, los arqueólogos y antropólogos que estudien los albores de la era digital. Para ellos, la vida cotidiana puede ser tan interesante como los momentos trascendentales que definen la épocas.

Este argumento trata de describir el pasado utilizando fuentes muy escasas pero que a partir de ellos logrando asi mantenerlo vivo y sin abandonar cada una de sus historias pasadas. Eliminar parte de su información privada siempre será satisfactorio para la persona que podría ser afectada y que su buen nombre podría también ser tachado por culpa de terceros.

Ese poder que se lo otorga a la persona o usuario para controlar su información y que esta no pueda ser manipulada por terceros y más cuando esta no tiene ningún interés periodístico o alguna relevancia histórica alguno puede a llegar a sonar desequilibrado. Puesto que siempre va existir un interés colectivo, un interés que va de parte a parte y se trata del hecho del propósito del derecho a ser diferentes a lo que se era mucho antes.

Cabe señalar que lo que se publica hoy en día en internet termina siendo un tatuaje indeleble, lo que muchos creían que un pasado acabaría siendo un pasado poco a poco se convierte en un presente eterno. Algo que toda vida lo va a perseguir, nada será un simple recuerdo. Es así como el derecho al olvido debe considerar conjuntamente un equilibrio entre el derecho personal y el derecho a la identidad. El derecho a ser olvidado debe ocultar como parte de su cambio una serie de hechos y acciones pasadas que son de conocimiento público, basada en la perspectiva de la privacidad, puesto que debe tener en cuenta las implicaciones que esta tendrían.

Este derecho desarrolla y protege un interés innegable y del cual constituye a un derecho de no solo ser diferentes de los demás sino de uno mismo, para que en evolución puedan eliminar identidades viejas y así formar unas nuevas para el bien de todos y de todos aquellos que en su momento salieron afectados por manos inescrupulosas. Este derecho toma forma pues de este se desprenden muchos otros y ya suele ser un instrumento jurídico el cual ayuda a de construir y reconstruir su propia identidad.

\section{LAS CRITICAS AL DERECHO AL OLVIDO}

El derecho al olvido ante la proyección y resultado de la cancelación y oposición ha sido blanco de numerosas críticas. Uno de los principales argumentos es que este derecho a la protección de datos iba a reescribir una nueva historia con respecto a la situación y/o problemática y así borrar todo con respecto a la información que se otorga. El contenido suministrado por las personas que suelen ser afectadas continuamente a los terceros se les imposibilitarí acceder a ellos de manera remota o fácil.

Los críticos dejan al descubierto que las relaciones sociales se basan en la información que se tenga unos de otros, su capacidad moral que tiene cada uno de ellos y el nivel de confianza que presentan entre sí. Es por esto que la aplicación del derecho al olvido sería un obstáculo al funcionamiento de dichos canales de información. A veces hasta las personas más cercanas 
tienden a utilizar esa información simplemente para perjudicar a la persona y seda más que todo por celos o envidia hacia la persona que suele ser afectada.

\section{CONCLUSIÓN.}

La globalización ha traído consigo muchos vacíos jurídicos lo que con llevada al desarrollo del derecho de las nuevas tecnologías, El reconocimiento del derecho al olvido frente a los motores de búsqueda constituye un decidido avance en el logro de una protección plena y eficaz de los derechos de las personas en el entorno a la era digital cuya implementación efectiva requerirá la colaboración de los gestores de los motores de búsqueda y las autoridades de protección de datos con el fin de establecer un marco relativamente claro y seguro para dar solución a los conflictos entre intereses privados e interés público subyacentes en la determinación del alcance del derecho al olvido.

A partir del análisis de la doctrina se lleva a cabo en este trabajo, el estudio de la normativa de protección de datos y, en particular, la obligación de eliminar de la lista de resultados los vínculos a páginas web en los motores de búsqueda que contengan datos personales inadecuados, no pertinentes o excesivos, especialmente, como consecuencia del paso del tiempo, ha habido detractores y partidarios con este nuevo concepto puesto que dicen que atenta con el derecho de libertada de expresión y no debería reconocerse como derecho al olvido sino con derecho desindexación a la de datos en las plataformas virtuales.

Se espera que después de la presentación de este trabajo de investigación, se tenga un panorama suficientemente amplio de la situación actual del derecho l olvido y el alcance de la derecho a la protección de datos personales en Colombia a partir de su aparición en Europa y su posterior evolución en España, hasta su actual reflejo en el ámbito jurídico Colombiano.

\section{BIBLIOGRAFIA}

Acedo, A. (2012). El derecho al olvido en internet como componente esencial del derecho al honor en el siglo XX. . En A. Sabaris \& C. Strapazzon (Dirs). Dirieitos Fundamentais Da Pessoa Humana, (pp. 191-219).

Álvarez Caro, M. (2015). Derecho al olvido en Internet: el nuevo paradigma de la privacidad en la Era digital. España: Editorial Reus.

Cerrillo Martínez, A. (s.f.). Neutralidad de la red y otros retos para el futuro de Internet. UOC-Huygens, p. 391-406.

Corte constitucional. (2014). sentencia T-020. Bogota, Colombia: M.P MENDOZA MARTELO GABRIEL EDUARDO
Corte Constitucional. (2015). Setencia T-277. Bogotá: M.P.MARÍA VICTORIA CALLE CORREA. Corte Constitucional Consejo Superior de la Judicatura Sala Administrativa . (1991) Constitución política de Colombia. Bogota, Colombia

Heredero, M. ( mayo 2012, ). Web 2.0: Afectación de derechos en los nuevos desarrollos de la web corporativa. En Revista Cuadernos Red de Cátedras Telefónica, (Número 6), (págs. pp. 1-40.). Madrid: Fundación Telefónica.

Llaneza, P. .. (septiembre de 2010). Derechos fundamentales e Internet. Revista Cuadernos de comunicación e innovación, (Número 85). pp. 54-57.

Martínez, R. (junio 2013, ). ¿Quién debería olvidarnos en Internet? Revista Actualidad Jurídica Aranzadi, (Nümero 864),pp. 1-3. Pamplona: Arazandi.

Miguel Asensio, P. A. (2015). Derecho privado en Internet, Estudios y comentarios legislativos. Madrid: Civitas.

Minero, G. (junio de 2014). A vueltas con el Derecho al olvido: Construcción normativa y jurisprudencial del derecho de protección de datos de carácter personal en e 30) $p$ 129-155.

Pica F, R. (2016). EL DERECHO FUNDAMENTAL AL OLVIDO EN LA WEB Y EL SISTEMA CONSTITUCIONAL CHILENO. Comentario a la sentencia de protección Rol NO 222432015 de la Corte Suprema. Estudios constitucionales, 309-318.

Platero Alcón, A. (2016). El derecho al olvido en internet. El fenómeno de los motores de búsqueda. Revista Opinión Jurídica, 15(29). 243-260. 